\title{
Can Leadership Behaviour Affect Quality \& Safety (Q \& S) in Complex Healthcare Environments?
}

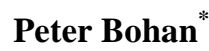 \\ Head of Organisational Health \& Effectiveness, Public Health Department John Moores University Liverpool, Merseyside UK \\ *Corresponding author: bohan869@btinternet.com
}

Received January 23, 2014; Revised January 30, 2014; Accepted April 01, 2014

\begin{abstract}
It is clear that leadership behaviour of executives in healthcare is considered to be of prime importance (Burke 2006), with key elements such as strategy, structure and process being vital for team and organisational effectiveness (Yammarino et al, 2008). This research identified that the executives interviewed in a Northwest acute Trust were clear on what type of leadership behaviour is expected of them; seeing themselves as transformational, setting clear goals and expecting the best from their teams. They also identified elements of autocratic and transactional leadership behaviour were required frequently in the achievement of targets such as waiting times and productivity. There was an acute recognition of the tensions between Q\&S and the target-driven approach required by commissioners and the current financial climate within the National Health Service. External drivers for Q\&S included losing foundation trust status which may result in loosing independence and being placed under special measures by monitor and receiving financial penalties. It was acknowledged the commissioners of services have huge power and influence over the direction of where the organisation concentrates effort to influence policy which could also provide tension with the Q\&S strategy. Finance and 'doing more for less' are constant themes, with competition to keep Q\&S on the agenda. Q\&S has a reputation for being problematic, many executives believed changing the organisational culture requires evaluation and effective engagement of staff. The aim of this paper is to analyse the complex relationships between leadership behaviour and Q\&S. The experiences of executives provide insight into the Q\&S agenda within Healthcare through change and dealing with complex issues including targets, motivation, behaviour, leadership, change and organisational culture.
\end{abstract}

Keywords: quality \& safety, Healthcare Environments, leadership behaviour

Cite This Article: Peter Bohan, "Can Leadership Behaviour Affect Quality \& Safety (Q \& S) in Complex Healthcare Environments?” American Journal of Public Health Research, vol. 2, no. 2 (2014): 56-61. doi: 10.12691/ajphr-2-2-4.

\section{Introduction}

It is clear that leadership behaviour of executives in healthcare is considered to be of prime importance (Burke 2006), with key elements such as strategy, structure and process being vital for team and organisational effectiveness (Yammarino et al, 2008). This research identified that the executives interviewed in a Northwest acute Trust were clear on what type of leadership behaviour is expected of them; seeing themselves as transformational, setting clear goals and expecting the best from their teams. They also identified elements of autocratic and transactional leadership behaviour were required frequently in the achievement of targets such as waiting times and productivity. There was an acute recognition of the tensions between Q\&S and the targetdriven approach required by commissioners and the current financial climate. External drivers for Q\&S included losing foundation trust status which may result in loosing independence and being placed under special measures by monitor which would result in financial penalties. It was acknowledged the commissioners of services have huge power and influence over the direction of where the organisation concentrates effort to influence policy which could also provide tension with the quality and safety strategy. Finance and 'doing more for less' are constant themes, with competition to keep Q\&S on the agenda. Q\&S has a reputation for being problematic, many executives believed changing the organisational culture requires evaluation and effective engagement of staff. The aim of this paper is to analyse the complex relationships between leadership behaviour and Q\&S. The experiences of executives provide insight into the Q\&S agenda within Healthcare through change and dealing with complex issues including targets, motivation, behaviour, leadership, change and organisational culture.

\subsection{Participants}

A purposive sample (Cresswell, 2007) using a volunteer strategy targeted the chief executive, chair of the board and senior executives. In-depth, semi-structured taped interviews were undertaken with nine executive managers.

\subsection{Methods}


A qualitative method was used in this study as it is the most appropriate tool specifically for the evaluation of leadership for three reasons; firstly it can be used differentially at organisational level; secondly, as leadership is a dynamic process interviews can add richness and depth to a study and thirdly, qualitative methods can aid socially constructed concepts from multiple perspectives (Conger and Toegel, 2002). The phenomological approach (Polit and Hungler, 1999) was taken as the methodology to gain the essence and perceptions of leaders, to understand how and why he or she comes to have the particular perspective (Cassell1999). The research was approved for ethics by the National Research Ethics Service (NRES) Committee Northwest.

\subsection{Data Analysis}

Data was captured using corpus analysis NVivo 9 qualitative software tool to store and categorise interviews (QSR International,2011). Interview evidence was placed on a data base, which allowed drilling down to uncover trends and look for similar phrases or words categorising evidence. This contributed to the semiotics aspect of leadership behaviour and how it influences quality and safety (Alvesson and Karreman, 2000). Coding of the descriptions enabled categories to emerge (Kan and Parry, 2004).

\section{Results-Leadership Style and Behaviour}

The analysis has been completed using the grounded theory approach, the questions being subdivided into categories to enable themes to emerge including opinions, experience behaviour, feelings, knowledge and sensory questions (King and Horricks, 2010). All of the executives understood what type of leadership style and behaviour is expected of them. The executives talked about the important issues to them which included being honest, inclusive and having a supportive management style. Providing individuals with clear accountability, empowering them to take responsibility and involving them in problem solving to deliver subsequent actions was also seen as important. Being very inclusive 'supportive' engaging' and 'educating' are all words frequently used to describe the leadership approach. The executives see themselves as transformational but identified the style would require adapting to the needs of the situation or outcome required The style of the Department of Health (DH) (2011) and commissioners was also seen as important the elements of autocratic and transactional leadership were required frequently in the achievement of targets (waiting times) quality matrices that provide evidence of outcomes to patients (numbers of hospital acquired infection) for example. It was also recognised that a directive style may be used in a medical emergency and the behaviour used in a critical situation may actually transfer into normal working activity if there is no stopping point and re-affirming of appropriate behaviour. The most inappropriate style of management to the executives was dictatorial bullying; with a number of executives who had witnessed or been a victim of bullying within the NHS in previous organisations. One executive had seen a charge nurse, 30 years ago in another premises being physically aggressive, assaulting patients and members of staff. A number of executives mentioned stress being a significant issue, and this could influence behaviour. Working to very autocratic managers was seen as being absolutely horrendous described by a number of executives.

\subsection{Quality \& Safety}

Q\&S is often described by executives in terms of patient safety and experience and as a single issue. This may be problematic for the workforce to thoroughly understand the vision of the organisation in relation to quality and safety if there is a mismatch of clarity between executive's views. Clinical outcomes were also significant and the term 'safety' was often described in terms of legislative compliance. The drivers for quality and safety with the current controls within the organisation include a range of safety matrices described as a pro-active approach that seeks out risks including stress management, learning from others particularly organisational failures, patient experience markers, patient trackers, feedback in a variety of dashboards, quality markers, health and safety executive, environmental health inspection requirements and Care Quality Commission (CQC) outcomes (CQC, 2011). The Board Assurance Framework or risk register was used to escalate risks; there was also recognition that data collection was just part of this process.

Clinical benchmarking was described with reference to Dr Foster, and clinical audits with executives wanting to empower people making sure that people have same vision and direction, facilitating others to reach their full potential. The key issue is for managers to have clear accountability and responsibility with an inclusive style. The executives had an understanding that transactional leadership styles are required sometimes in a health and safety context, for example when staff must wear head protection on a construction site. The financial challenges are real and the consequences of losing control significant so there has to be a strong directive leadership style to take control. The external drivers for Q\&S included losing foundation trust status with financial penalties from the commissioners.

All saw the external drivers as a major influence on internal policy development and control. The data collection system described internally may not be all encompassing and provide all the detail required when triangulated, finance and doing more for less are constant themes and how there is competition to keep Q\&S on the agenda when financial pressures drive the changes, if there is no strong leadership for Q\&S then the issue may not be driven forward. The raw data may only reveal details of what has been identified as needing to be measured; attitude and behaviour which require different measuring techniques have not been evaluated (Ipsos MORI, 2010). A large increase in incidents would involve the commissioner becoming very aggressive about trying to stop the number of incidents occurring.

\subsection{Cultural Aspects of Leadership}

Participants described the culture and behaviour taking many years to change. Executive $\mathrm{C}$ described a culture taking a long time to change but the approach appears to be successful up to now (Pigeon and O’Leary, 1994). Many executives described quality and safety as 
problematic as it was difficult to explain to staff and Q\&S means different things to different people.

\subsection{Lessons Learned}

Lessons learned appear fragmented and there was no clear way to determine if lessons were being embedded. Stepping Hill was mentioned a number of times by executives and how difficult it would be to stop a rogue employee wanting to cause damage, despite having good governance systems in place. Executives stipulated that we are much better at embedding action plans from incidents when staff are directly involved in the decisions. The Mid Staffordshire NHS Foundation Trust Inquiry (Department of Health, 2010) was mentioned by many executives and that it could happen, but they had worked hard to ensure the big lessons are learned from such incidents however the smaller learning is probably patchy.

\section{Discussion}

The leadership behaviour is vital to support effective Q\&S and target driven approach described by many executives from commissioners. Broadbent (2004) describes many behavioural-based systems as being grounded in transactional management theory when examining safety outcomes using this style the results are often poor. Reliance on policies and procedures is likely to fail if staff are not clear on structure and behaviour that supports quality and safety. The problem with the current conflict seen in management style between target driven transactional approach and the preferred transformational approach is ambiguous.

The data collection system described by executives is predominantly being externally imposed (Bowland and Fowler, 2000) and likely to have punitive or negative consequences. Marshall et al (2000) summarised the available evidence that is supplied by quality data often does not influence patient choice significantly.

Davies (2009) highlighted that when surgeons and clinicians were actively using the data to improve quality outcomes for patients it was the best use of such information.

The increase in reportable incidents creates a safety paradox in that it appears that things are getting worse with increased reporting to regulatory authorities, when in fact knowledge of the risks enables the organisation to clearly identify significant areas of concern and reduce poor safety outcomes (Schofield, 2007). 'The psychology that a mistake equals bad' coupled with the blame culture that is often

prevalent in healthcare organisations does not encourage willingness to report errors' (Kennedy and Mortimer, 2007) however this does not appear to be prevalent within the organisation as reporting has increased considerably within the past 12 months.

\subsection{Behaviour of Leaders}

Executives described the types of behaviour they had witnessed:-

'I like to be seen as inclusive and seen as a good communicator, respectful of people's individuality and then staff feel more empowered to do more'.

'I think if you look at most NHS leaders they were very directive and pacesetting my 360 said something like that but part of that style you only have to look up the style of the Department of Health and its cascaded down so you set a target that sets the pace and targets have got to be delivered in very strict timelines and if there is a failure there is a kicking all the way down the line so that creates the behaviour because you are not truly autonomous even if you are a foundation trust you still have to comply with these monthly targets whether you think they are good or bad'.

'Engaging staff feeding back to staff the consequence of not getting the quality right first time is important however I've seen individuals frankly reduced to tears on occasions, with inappropriate behaviour in the public and in the working environment so from that perspective I have seen it I haven't seen it in this organisation'.

'Not at this trust but yes bullying, very directive lack of support very demanding you will do, but not listening to why you are struggling there are some very significant building blocks that are not there'.

'Yes just the best word is bullying don't care what you say your heads going to be cut off if you don't achieve it I've worked in an environment where people have been dictatorial bullying a lack of transparency and a lack of credibility It ranges from people not listening to people going down a blind alley without facts people being rude or aggressive'.

'A senior staff member ranting and gesticulating at staff'.

There is a big public expectation people expect far more than they used to Monitor may not be as powerful as the external driver are now of the Care Quality Commission (CQC) because unannounced visits or planned inspections evidence of outcomes effectiveness it's not something the NHS has ever had before. We could lose our foundation trust status. The bar is set for us undoubtedly I think if you look in simplistic terms the mortality rate within the organisation has significantly reduced over the past five years, reduced our length of stays reduced our complication rates have reduced A\&E have reduced all of those issues are as a result of being centrally imposed Financial penalties, if you don't achieve them and in terms as ourselves as a Foundation Trust unless we meet our compliance framework then we would lose our Foundation Trust status External inspections, HSE, Environmental Health, External Agencies like CQC, Links professional; agencies like CPA in pathology Regulation is expected and you will be held to account very strongly if that is an issue It's important we pick up the right things, 'it's alright we have 300 dashboards but it is possible to be bombarded by too much and need to prioritise these sorts of approaches If we had a large increase in H\&S incidents the Commissioner would be very aggressive about us intervening and stopping this problem We need to move away from a culture where the noise is the loudest we give it the most attention.

Quality is about making sure we monitor the effectiveness of the systems we actually put in place Fit for purpose, acceptable to the user and something that is perceived as high value in terms of what it delivers for an individual's safety Clinical effectiveness and good experience, quality is about doing what we do and is right first time From a qualitative point of view it's delivering the service that the patient needs or it is clinically indicated, with courtesy dignity and respect 'I think my 
perception of quality is different to your perception of quality therefore it is a very difficult aspect to deliver It is based around the trust's values, the other based around the need of patients in care Health and safety, mandatory training, and so on, and the promotion of a culture of safety and risk assessment and they are the formal processes on safety on effectiveness not only about clinical effectiveness. Safety is about making sure we are all operating within the parameters that we are within our terms of reference to operate, making sure we are up to speed with legislation.

\subsection{Culture Aspects of $Q \& S$}

The cultural aspects of quality and safety cannot be underestimated, Marsh (2003) has identified that the most ineffective way to get individuals to change is to tell them to change in a transactional manner. The person factor is absolutely vital when we consider the practicalities of moving beyond a compliant to a pro-active safety culture. The function of a leader to produce outcomes through performance measures are well understood, Burke et al (2006) identified that leadership behaviour are differentially related to team performance, at its lowest point leadership behaviour accounted for $4 \%$ variance, while at its highest accounted for 31\% improvement in performance. Even an increase in productivity of $4 \%$ is significant at the lowest level and gives weight to the notion that any effort to improve leadership behaviour can improve productivity and is a worthy area to examine further. Many of the executives described having to tailor their style to specific needs of each person or work task, however there is another element which needs to be considered and that is dependent on skills maturity (Cohen, 2007). Hersey and Blanchard (1982) have described the psychology of work as a behavioural theory, when subordinates maturity is low, leaders need to focus on structure, when maturity is high, structure can be de-emphasised.

We have to move away from a culture of where the noise is the loudest we give it the most attention because in my experience it's where the noise is quietist you have the biggest problems It's been a culture change and it's taken four or five years to begin to embed you don't change cultures and behaviours overnight, often culturally people only hear the message about finance and targets and they don't here the message about Q\&S. The cultural change is the most difficult thing to change It takes a long time to change a culture I think we are getting there and we are a lot further down that road 'I think you can easily erode a quality and safety culture very quickly by what you do by one act of how you lead and your behaviour and its quicker to do that in a minute or two, and it takes years and years to build a culture but it can be eroded very very quickly by a few bad examples'.

The cultural aspects of the organisation require further evaluation using a cultural survey tool (National Patient Safety Agency, 2004) particularly in relation to how leadership behaviour affects safety outcomes (Barling and Zacharatos, 1999).

\subsection{Is $Q \& S$ Problematic}

One Executive believed Q\&S is problematic in practical terms theoretically it's a no brainer why would you undertake practices that might injure yourself or others Yes, partly because it means all things to all people Oh I hugely I mean the yes its problematic in this day and age and in the public sector you know to do it to its enth degree it doesn't come without a price tag, so its problematic to strive to the text book Undoubtedly I think the very nature of dealing with human interaction as I think my perception of quality is different to your perception of quality'.

Although major issues such as Mid Staffs had influenced the board and changed the corporate approach to process with less reliance on external assessments and data systems. The acceptance that the leadership style requires adapting to a situation is clear, but the more transactional approach (Judge and Piccolo, 2004) required in accident and emergency (A\&E) departments for example, must not become the normal style of management as this can become destructive to all staff involved.

Executives described key issues such as;-

'I think as instances happen at the likes of Mid Staffs you get big reports that come out action plans, big learning for all organisations big dissemination unfortunately we always have things like that happening and therefore there is always that re-active learning to prevent the organisation having similar incidents'. There have been significant learning with the outcomes identified within he Francis report (Francis 2013) the changes have looked at key elements of behaviour that relate to pay and a duty of candour which requires staff to raise concerns with senior staff and not leave risks unresolved. The changes are driven by the public expectation and government requirements which are constantly driven by experiences that happen elsewhere.

'I am being brutally honest I think we do learn and I think the response to that learning is slower than it should be I think we learn to some degree but we don't really understand as an organisation what we are learning the one thing we do in the organisation is we measure anything I think we are working very hard to do that and there are some good examples where we have done that like infection control is a good example and I think we have a long way to go on comments on communication within complaints where we get quite a significant number of where that is cited as the problem I don't think it is specific to us I think it's an NHS problem'.

One executive believed that once it becomes policy it gets embedded but was not clear if the learning has worked as it was difficult to evidence. 'The learning lessons and holding up to the organisation is a mirror look at what has happened there. It could easy happen here so what have we got in place as in Mid Staffs. We made big of them but I guess the smaller learning and follow up in isolation it probably patchy'. Lessons learned you've done the policies you put a policy in policies great as it picked up on the lessons learned the director moves away and the first thing they do is they don't like this policy and you can lose your memory to why you had the initiative in the first place.

\section{Recommendations}

Transformational leadership style is evidenced in the responses this must be used to strive towards higher levels of performance from subordinates producing higher moral 
and ethical standards within staff groups (Bolder and Gosling, 2003). This is important to enable followers to enact what a leader emphasises by their behaviour. A strong strategic narrative giving a line of sight between the job role, subordinates responsibilities (Andreescuv and Vito, 2010) and the organisations vision (Macleod and Clarke, 2009) is required to ensure effective employee engagement that produces positive worker behaviour (Harter et al, 2002). The relationships between indicators and how these address-long term performance goals is a critical element of patient care (Patel et al, 2008).

The engagement of clinicians to develop targets and financial outcomes will improve quality and safety performance. Evidence should also be obtained from the complaints and PALs (Patient Advisory Liaison Service), thus ensuring outcomes are achieved against policies and procedures (MIAA, 2011). A specific executive leadership programme is required to align vision, quality, norms and supportive measures to divisions. Accountability for leadership programmes requires clarity to provide more effective feedback to the centre that result in real change in the organisation. Projects require linking to hospital management and the implementation process of the Quality Improvement Strategy (Duckers et al, 2011). Lessons learned appears to be an issue that requires reviewing with many of the executives not being completely sure that lessons were being embedded across the whole organisation.

\subsection{Policy Implications}

The policy implications of this paper require highlighting to the new clinical commissioning groups held to account by the commissioning board (NHS Commissioning Board, 2012) that absolute commitment to targets and finance increase the risk of organisational failure regarding quality and safety. The target driven approach is important but may produce the style of management that may sideline the quality and safety agenda if not handled appropriately. The potential for the aggressive pursuit of data may result in a culture that reverts back to under reporting due to the negative response to incidents from commissioners being pursued. The study adds to the notion that positive engaging behaviour can influence quality and safety outcomes, behaviours that are developed as organisational norms can improve the quality of outcomes to patients, staff and enhance performance.

\section{Key Points}

The commissioning boards' behaviour and the conflict described between finance, targets and quality and safety appears to be a constant issue. This approach could have significant implications on staff and patient outcomes. The actions words and behaviour's of senior hospital leaders have a profound effect on what happens to patients and staff executives need to define the strategic vision for Q\&S more succinctly to staff, as the description of quality and safety varied from each executive. The leadership programme requires effective evaluation of change in management style and behaviours to ensure it makes a real difference to the whole organisation.

\section{References}

[1] Alvesson M, Karreman D (2000) Varieties of discourse: On the study of organizations through discourse analysis. Human Relations 53(9): 1125-49.

[2] Andreescu V, Vito G (2010) An exploratory study on ideal leadership behaviour: the opinions of American Police Managers. International Journal of Police Science and Management 12(4): 567-83.

[3] Barling J, Zacharatos A (1999) High performance safety systems: management practices for achieving optimal safety performance. Presented at 25th annual Meeting of the Academy of Management, Toronto, Canada.

[4] Bolden R, Gosling J, Marturano A, Dennison P (2003) Leadership Theory and Competency Frameworks. University of Exeter Centre for Leadership Studies, Exeter.

[5] Boland T, Fowler A (2000) A systems perspective of performance management in public sector organisations. Journal Public Sector Management 13: 417-46.

[6] Broadbent DG (2004) Maximising Safety Performancevia Leadership Behaviour. Available at: http://www.transformationalsafety.com/documents/Maximising_S afety_Performance_via_Leadership_NP.pdf (accessed).

[7] Burke C, Stagl K, Klien C, Goodwin, G, Salas E, Halpen S (2006) What type of leadership behaviors are functional in teams? A meta-analysis. Leadership Quart 17(3):288-307.

[8] Care Quality Commission (2011) Quality and Risk Profile. Care Quality Commission, London.

[9] Cassell C, Symon G (1999) Qualitative Methods in Organisational Research: A Practical Guide. 4th edn.Sage Publications Ltd, London: 15.

[10] Cohen MH (2007) What You Accept is What You Teach: Setting Standards for Employee Accountability. $2^{\text {nd }}$ edn. Creative Healthcare Management, Minneapolis, MN: 52.

[11] Conger A, Toegel G (2002) A Story of Missed Opportunities: Grounded Leadership Theory and Research. Information Sage Publication, Greenwich, CT: 175-97.

[12] Cresswell JW (2007) Qualitative Inquiry and Research Design: Choosing Among Five Approaches. 2nd edn. Sage Publication India Limited, New Dehli.

[13] Davies H (2009) Measuring and Reporting on the Quality of Healthcare. NHS Quality Improvement Scotland, Edinburgh.

[14] Department of Health (2010) Robert Francis Inquiry report into Mid-Staffordshire NHS Foundation Trust. Deparmtnet of Health, London.

[15] Department of Health (2011) The Health and Social Care Bill. 21st October. Department of Health, London Dückers ML, Wagner C, Vos L, Groenewegen PP (2011) Understanding organisational development, sustainability, and diffusion of innovations within hospitals participating in a multilevel quality collaborative. Implement Sci 6: 18.

[16] Harter S, Snyder S, Lopez S (2002) Authenticity Handbook of Positive Psychology. Oxford University Press, London: 382-4.

[17] Hersey P, Blanchard K (1982) The Management of Organisational Behaviour. 4th edn. Prentice Hall, Englewood Cliffs, NJ.

[18] Ipsos MORI (2010) Engaging for success: a review of the Mcleod report. Office of the Public Sector Kew.

[19] Judge A, Piccolo R (2004) Transformational and Transformational and transactional leadership: a metaanalytic test of their relative validity. J Appl Psychol 89(5): 755-68.

[20] Kan M, Parry W (2004) Identifying paradox: A grounded theory of leadership in overcoming resistance to change. Leadership Quart 15: 467-91.

[21] Kennedy C, Mortimer D (2007) Risk management in IVF. Best Pract Res Clin Obstet Gynaecol 21(4): 691-712.

[22] King N, Horricks C (2010) Interviews in Qualitative Research. Sage Publications Ltd, London.

[23] Macleod D, Clarke N (2009) The Macleod Review. Macleod Report. Ofice of Public Sector Information, Kew.

[24] Marshall MN, Shekelle PG, Leatherman S, Brook RH (2000) The public release of performance data What do we expect to gain a review of evidence. JAMA 283(14): 1866-74.

[25] Marsh T (2003) Pillars of a safe society. Health and Safety Practitioner 21(2): 22-4.

[26] Merseyside Internal Audit Agency (2011) Essential Standards for Quality and Safety: How Well AreOrganisations Complying? MIAA, Liverpool. 
[27] National Patient Safety Agency (2004) Seven Steps to Patient Safety: An Overview Guide. 2nd edn. NPSA, London.

[28] NHS Commissioning Board (2012) A Special Health Authority. Available at: www.commissioningboard.nhs. com (accessed 26 March 2012).

[29] Patel B, Chaussalet T, Millard P (2005) Balancing the NHS scorecard. Eur J Oper Res 185: 905-14.

[30] Pidgeon N, O’Leary M (1994) Organisational safety culture: implications for aviation. In: Johnston N McDonald N, Fuller R, eds. Applications of Psychology to the Aviation System. Avebury Aviation.

[31] Polit D, Hungler B (1999) Nursing Research Principles and Methods. 6th edn. Lippincott Williams and Wilkins, Hagerstown, MD.
[32] QSR International (2011) NIVIVO9 Data Base System. Available at: www.qsrinternational.com/products_nvivo.aspx (accessed 26 March 2012).

[33] Schofield H (2007) Embedding quality improvements and patient safety at Liverpool Women's NHS Foundation Trust. Best Pract Res Clin Obstet Gynaecol 21(4) 593-607.

[34] Yammarino F, Dionne S, Schreiesheim C, Dansereau F (2008) Authentic leadership and positive organizational behavior: A meso multi-level perspective. Leadership Quart 19(6): 693. 